\title{
Integration of GIS, Traffic Volume, Vehicular Speed and Road Grades Related-Air Pollution in Amman
}

\author{
Eman Shehadeh \\ American University of Madaba \\ Madaba, Jordan \\ E.shehadeh@aum.edu.jo
}

\begin{abstract}
This research combines field data and analytical approach into spatially map Air pollution levels due to traffic movements, vehicle speeds and grades of roads at relatively high traffic volumes signalized intersections in Amman; capital of Jordan .

The study was conducted by collecting traffic and air pollution data at twelve locations in four streets, each street located in a different zone. Also data were collected at three different highly congested traffic periods. The highest air pollution level was measured at 7 th circle in Abdullah Goshah street, where was the maximum Average traffic volume. And the least air pollution level of the studied areas was at Anas Bin Malek Street so that it can be an acceptable residential area. Results showed clearly that air pollution levels reach maximum values at or near the traffic signals and decrease gradually when there is an increase in the distance from signals. Also, increasing in road gradients leads to a decrease in speed of vehicles, this leads to an increase in the pollutants concentrations.

The highest air pollution concentrations were 0.7, 0.6, 9.9, and 0.6 (in ppm) of NO2, SO2, CO and SPM respectively. The R-square value, square of relative coefficient, of the relationships between $\mathrm{NO}$, SO2, CO \& SPM concentrations and traffic volume were about: $0.9135,0.8822,0.8977$, and 0.8934 respectively. It is seen that traffic flow has the highest impact on SO2, NO2, CO \& SPM concentrations. This study has shown that the levels of these pollutants are above the recommended levels World Health Organization (WHO) in most parts of the studied areas, indicating a need for a regular air quality monitoring, traffic management system and reliable strategies for keeping pollution caused by harmful chemicals under safe level have to be developed and used routinely.
\end{abstract}

Keywords: Emission, Pollutant, Vehicles, Traffic Volume, Air Pollution, Road Grade.

\section{Introduction}

In fact, some signalized intersections showed higher air pollution levels than the acceptable or the standard ones. Twodimensional (2D) vector and raster maps of Air pollution levels, at different periods of time for signals' areas and between them, were spatially displayed. Results showed that the study could be useful for city planning and other environmental management applications for the purpose of: 1) temporal monitoring and queries of air pollution level changes as function of time, 2) spatial queries to find highest Air pollution disturbance location and its time of the day, 3) development of online Air pollution information system, and 4) using Air pollution level based maps as indicators for the purposes of booming or depression in land pricing and selling.

Urban areas with high air pollution disturbance are commonly not attractive as residential zones. Therefore, the land prices and people motivation to live near high air pollution level areas would be decreased. Moreover, the availability of spatial air pollution level maps would be useful for planners as well as citizens for their decision-making strategies and scenarios.

Thus, planners could select urban zoning design with the least environmental impact. Further, integrating air pollution data with spatial and location data would quantify air pollution effects in a digital maps domain. These maps could quantify air pollution levels and its effect based on areas, population density, number of citizens and buildings, and type of buildings. Moreover, selecting a threshold air pollution level would classify urban area into acceptable or not acceptable zones for different usage such as residential, industrial and commercial.

This project will present and analytical approach to spatially map air pollution levels at different time of the day in order to assist decision-making and planning tasks at the municipalities` levels. It is anticipated that this study will open the door to apply standardized methods to quantify air pollution effects and to increase air pollution studies in an automated manner. 2. Objective 
The aim of this study is to understand the relationship between air pollutant concentrations and traffic volume (mainly), speed and road grades. In this study, concentrations of CO, NO2, SO2 and SPM were measured at various sampling sites at different period of times to help planner, Decision makers, researchers and people.

\section{Literature Review}

Some of the worst pollutants are nitrogen oxides, carbon monoxide, sulphur dioxide, lead, and suspended particulate matter. According to the Environmental Protection Agency (USEPA, 2007).

Schwela, (2000), concluded that many studies have confirmed adverse health effects associated with high concentrations of transport-related pollutants.

Abu Al-Salem and Hazim, (2015), concluded that the characteristics of air pollutants under different traffic flow conditions and different road grades were ; $\mathrm{SO} 2, \mathrm{NO} 2, \mathrm{CO} \&$ TVOC's concentrations were measured with traffic variables. The ratios of SO2, NO2, CO \& TVOC's concentrations different road grades were 2.5- 5.2 showing the influence of grade effects.

Spatial GIS shows a great potential in mapping of traffic noise and other parameters levels in the domains of temporal mapping, spatial mapping, and selection of suitable areas for residential or other land use standards (Obaidat,, 2008)

Duffy et al. (1996) and Rogak et al. (1998) studied the air quality in Sydney and Canada, respectively. They similarly discovered that the main air pollution source was the burning of vehicle engine gasoline or diesel, and that $\mathrm{NO}$ and $\mathrm{CO}$ was the main air pollutants.

\section{Methodology}

Short term measurements (15-minute averages) of gaseous pollutants (SO2, NO2, CO \& SPM) were conducted at different locations. Air pollutants of Nitrogen dioxides; NO2, Carbon monoxides; SPM, CO and Sulphur dioxides; SO2 measurements were conducted based on Electro-chemical Cell method using portable toxic gas analyser.

All the aforementioned instruments were calibrated at multipoint before and after the experiment according to the usual routines of quality control.

The data collection, which consists of the traffic flow survey, was conducted on November 9-20, for four working days, at 12 locations of 4 streets. The traffic flow survey involved the observation and collection of traffic flow data from twelve intersections points along major arterial roads using video cameras and direct counting method. The time periods of taking measurements of data from the selected sites was carried out in three time periods for duration of four working days of the week. These times are as follows:

- 7.30 am - 9.30 am Morning peak hours

- $1.30 \mathrm{pm}-3.00 \mathrm{pm}$ off peak period

- $9.00 \mathrm{pm}-11.00 \mathrm{pm}$ Evening peak hours

Air pollutants data were conducted based on Electro-chemical cell method using portable toxic gas analyzer.

Air pollution levels due to traffic movement and traffic volume variations were measured at different signalized intersections though twelve days. Air pollution data were studied at 8- signals of 4-streets at 4- zones in Amman. As far as air pollution is concerned, these immigrants - without any doubt- contributed negatively to the environment. The zones mainly represented residential areas. Table (1) shows the characteristics of the studied streets.

Table 1: Characteristics of studied streets.

\begin{tabular}{|c|c|c|c|c|}
\hline Street Name & Lane-Way & Zone Of Street & Gradient \% & Type Of Zone \\
\hline Addustour & 2 Lane-2 Way & Badir & 7 & Residential \\
\hline Abdullah Gosheh & 3 Lane-2 Way & Wadi Assir & 0 & Residential \\
\hline Anas Bin Malek & 2 Lane-2 Way & Ras Alain & 9 & Residential \\
\hline AlHurryah & 3 Lane-2 Way & Albunyyat & 5 & Residential \\
\hline
\end{tabular}


Traffic signals were located at intersections having three and four legs and having different traffic volumes and geometric parameters including roadway slope, number of lanes and lane width.

The data of Air pollution were collected at two locations in each street:

1. At traffic signal approaching legs.

2. At the mid-point between traffic signals.

Traffic Air pollution levels of the signalized intersections were measured near the traffic signal where the first vehicle stopped. However, air pollution levels between signals were measured at mid distance. Figure1 shows the studied streets and traffic signal locations that Air pollution levels were measured.

This research involved the collection of data on the following air quality parameters: Carbon Monoxide (CO), Nitrogen Oxides (NO2), Sculpture Oxides (SO2), and solid particulate matters (SPM). Air quality parameters were measured using potable toxic gas analyser based on Electro-chemical cell method, which is an automatic instrument that measures $\mathrm{CO}, \mathrm{NO} 2$, SO2, and SPM. Data were presented graphically and in tables, while further analysis was based on descriptive and explanatory (inferential) statistics. Figure (1) shows the studied streets and traffic signal locations that Air pollution levels were measured.

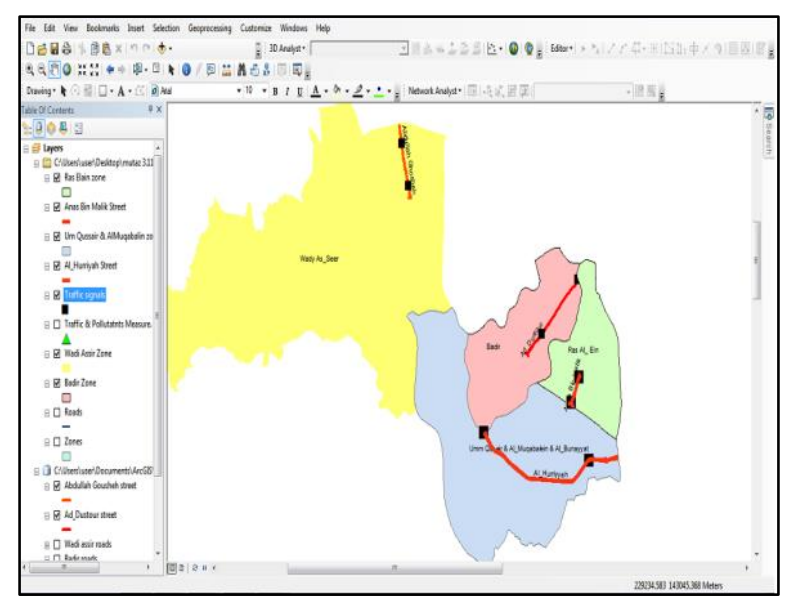

Fig. 1: Studied streets and Traffic Signal locations.

\section{Results and Discussion}

\subsection{Plotting and Mapping}

The variables involved in the emigration of traffic air pollution may include traffic volume, road geometry, traffic speed, heavy vehicles existence, surface texture and distance from the traffic signal. However, the main factor affecting equivalent air pollution levels is traffic volume. It was quite clear that at regions known with its high traffic volumes, as traffic volume increases, higher equivalent air pollution levels were monitored, figure (2) shows the relation between them. 


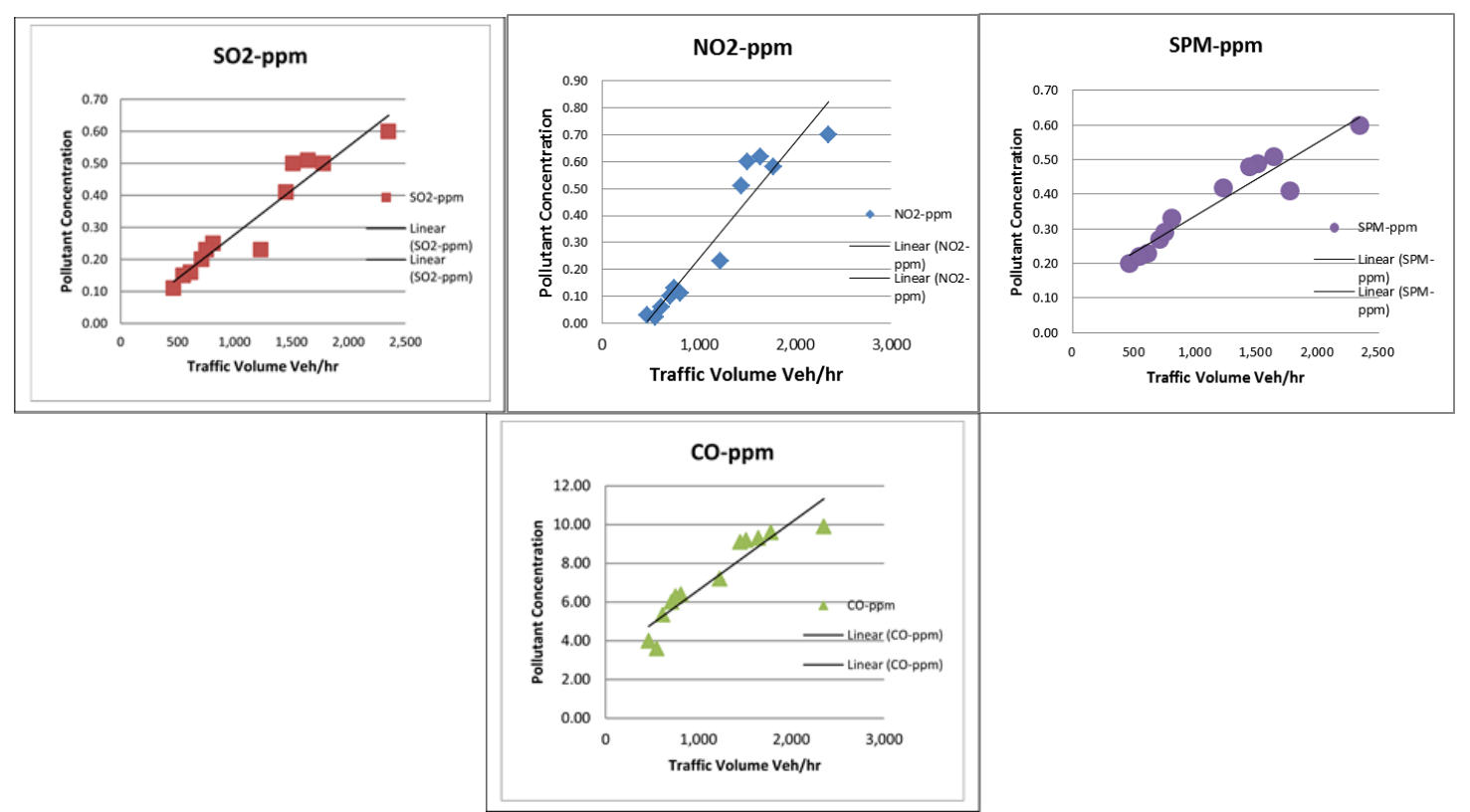

Fig. 2: Best fit linear straight line for NO2, CO, SO2, and SPM according to Traffic volume in Peak Period.

Moreover, as distance from the traffic signal increases the effect of increased traffic volume on air pollution becomes of less importance. That was because of the increase in the effect of other variables such as, traffic speed, on the equivalent air pollution levels as distance from the signal stop line increases.

At far distances from the signal stop line, effect of traffic speed on equivalent air pollution levels was higher than the effect of traffic volume. Also, as gradient of the approach increases the air pollution levels increases. This is due to the fact that vehicles exhibits higher engines horsepower, as the upward gradient of the road increases. In fact, the maximum air pollution levels were found to be highly affected by the existence of heavy vehicles on the intersection. As the number of heavy vehicles increases, the maximum air pollution levels increase. Equivalent air pollution levels were affected significantly by distance from the intersection. This may refer to that equivalent air pollution levels at distances from the signal stop line were less than those at signal stop line due to less generated engines horsepower as distances from the signal stop line increase.

Spatial modelling techniques could also be used to simulate the spread of air pollution data due to traffic volume, and to locate the suitable boundaries for the zone area according to international standards. Using the acceptable threshold air pollution level data, city planners could locate and classify the suitable zones and their residential, commercial, or industrial type. For example, using $9.0 \mathrm{ppm}$ of $\mathrm{CO}$ as a maximum acceptable air pollution level threshold value for residential areas in Jordan. Also spatial map shows the predicted boundaries of the acceptable zones were citizens can build their houses without noticeable high Air pollution level. Figure (3) shows the locations of exceeded air pollutant concentration of SO2 compared with maximum WHO and NEPM air pollution Values. We conclude that those areas are not suitable for residential ones and we need there solutions for the high pollution. 


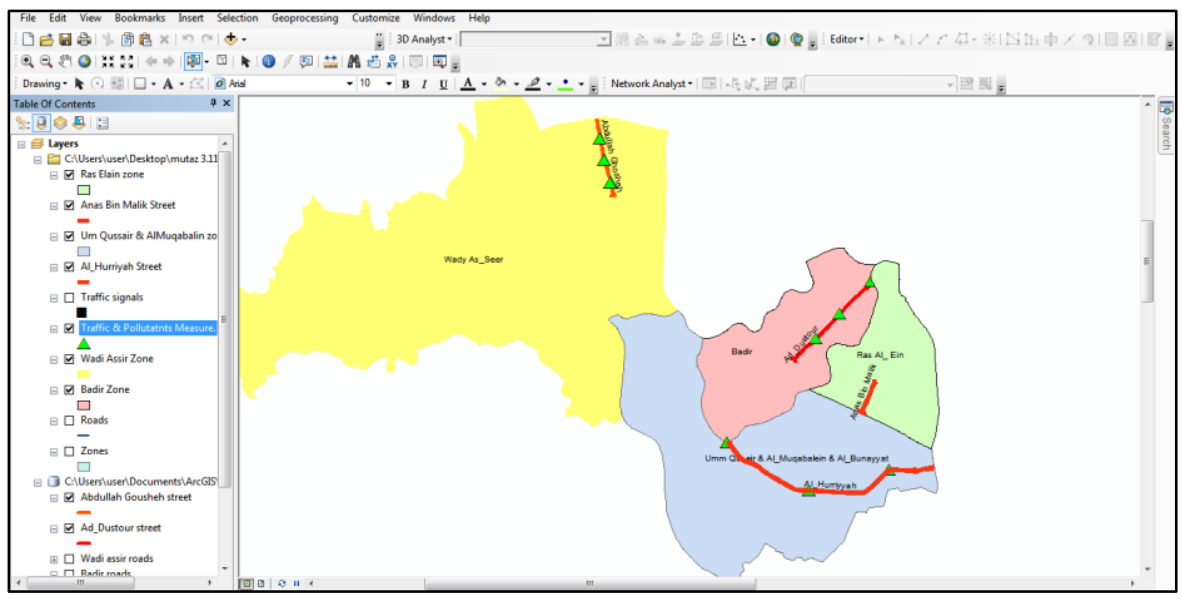

Fig. 3: Locations of Exceeded SO2 (more than $0.20 \mathrm{ppm}$ ).

Figure (4) shows that 200 meter buffering done around the studied locations, the dark black areas with high Air pollution levels are not suitable for residential areas; however, the bright areas with less Air pollution levels are the most suitable ones. And it shows that the highest air pollution level was measured at 7th circle in Abdullah Goshah street, where was the maximum Average traffic volume.

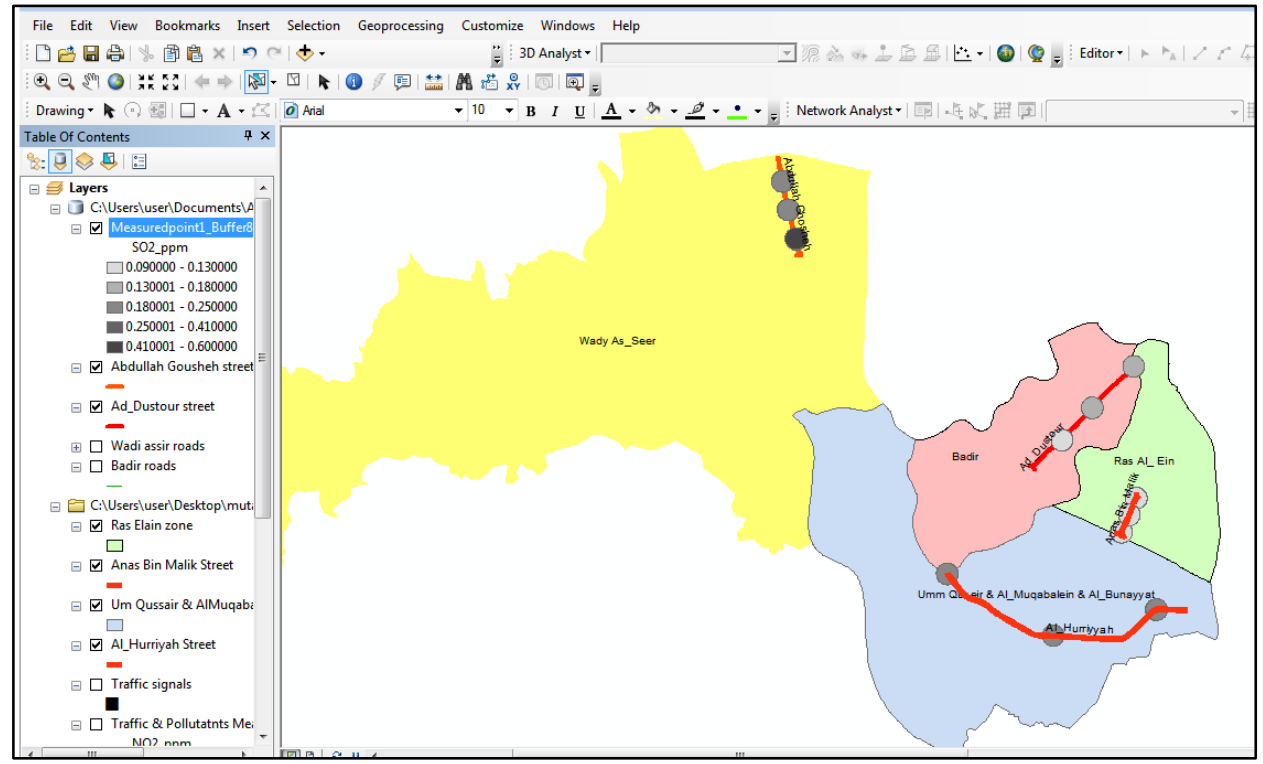

Fig. 4: Spatial map for Average pollutants concentrations.

\subsection{Regression Analysis}

The relationships of the measured roadside $\mathrm{CO}, \mathrm{SO} 2, \mathrm{SPM}$ and NO2, mass concentration and all traffic passing through the intersections are shown in the table (2). 
Table 3: Correlation coefficients for relationship between air quality parameters and Traffic Volumes.

\begin{tabular}{|c|c|c|c|c|}
\hline \multicolumn{3}{|l|}{ Coefficients } & \multicolumn{2}{|c|}{ Parameters } \\
\hline & $\mathrm{NO} 2$ & $\mathrm{SO} 2$ & $\mathrm{CO}$ & SPM \\
\hline$R^{\wedge} 2$ & 0.9135 & 0.8822 & 0.8977 & 0.8934 \\
\hline Adjusted $\mathrm{R}^{\wedge} 2$ & 0.9109 & 0.8787 & 0.8947 & 0.8903 \\
\hline \begin{tabular}{|l|}
$\mathrm{F}$ \\
\end{tabular} & 358.9840 & 254.6290 & 298.5900 & 285.0971 \\
\hline Sig F & 0.0000 & 0.0000 & 0.0000 & 0.0000 \\
\hline
\end{tabular}

*Source: Analysis of fieldwork data.

Simple linear regression analysis is used to test the strength of the significant factors in affecting the pollutant concentrations linked with studied locations, by get developed models from SPSS software. Table (4) shows those relations

Table 4: Models represent the average pollutant concentrations (CO).

\begin{tabular}{|c|c|c|c|c|}
\hline NO & Models & $\mathbf{R}^{2}$ & F-value & P-value \\
\hline $\mathbf{1}$ & Pollutant conc. $=0.00217 * \mathrm{~V}$ & $\underline{\mathbf{0 . 9 3 4}}$ & 358 & $3.44 \mathrm{E}-18$ \\
\hline $\mathbf{2}$ & Pollutant conc. $=0.392^{*} \mathrm{G}$ & 0.895 & 279 & $3.38 \mathrm{E}-16$ \\
\hline $\mathbf{3}$ & Pollutant conc. $=0.0231^{*} \mathrm{~S}$ & 0.884 & 137 & $7.35 \mathrm{E}-13$ \\
\hline
\end{tabular}

From figure (5) it is clear that an increase in gradients leads to an increase in air pollutants concentrations because of the decrease in vehicular speed at upgrades, which consequently results a production of high amount of emissions from vehicles.

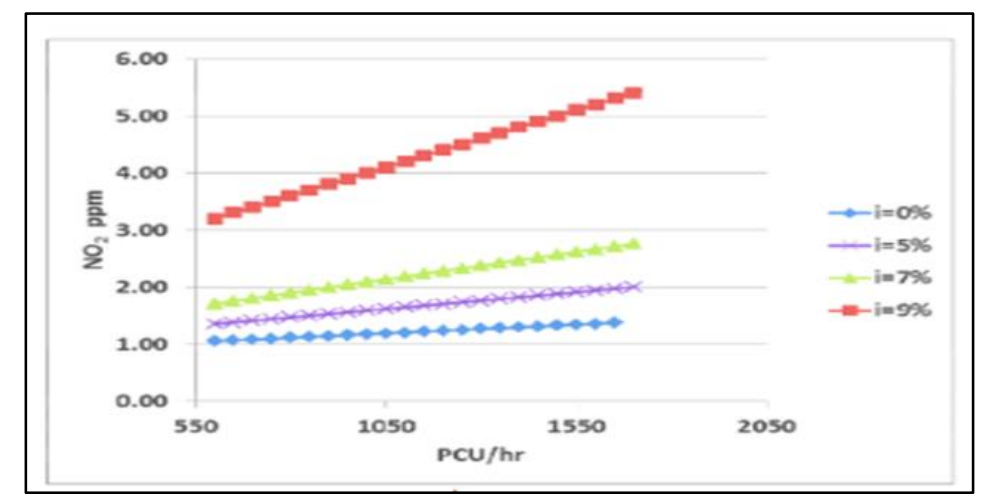

Fig. 5: SO2 (ppm) Vs. Traffic volume with Grade (\%).

Multiple linear regression is used to provide the best multivariable equation that includes the most significance independent variables. The model shown in table (5) is significant. So it is possible to use in predicting the pollutants concentrations in any location in Amman.

Table 5: The developed model related to the significant independent variables (CO). 


\begin{tabular}{|c|c|c|c|}
\hline Models & $\mathbf{R}^{2}$ & F-value & P-value \\
\hline $\begin{array}{c}\text { Pollutant conc. }= \\
3.609+0.00225 \mathrm{~V}+0.434 \\
\text { G+0.0283 S }\end{array}$ & $\underline{\mathbf{0 . 9 4 6}}$ & 412 & $5.68 \mathrm{E}-22$ \\
\hline
\end{tabular}

\section{Conclusion}

This study has shown that the levels of these pollutants are above the recommended levels of (EPA), EPNA and WHO in most parts of the studied areas, indicating a need for a regular air quality monitoring and management system. Reliable and robust strategies for keeping pollution caused by harmful chemicals under safe level have to be developed and used routinely. So the main concluded points are:

- Spatial maps generated from air pollution levels of traffic movements could be used as indicators for land prices, human beings comfort levels, commercial activities, and environmental or climatic factors levels based on measured air pollution level are also possible.

- The highest air pollution level was measured at 7th circle in Abdullah Gosha street, where was the maximum Average traffic volume.

- And the least air pollution level of the studied areas was at Anas Bin Malek Street and it can be an acceptable residential area.

- Peak hour of pollutant concentrations was the morning period, (07:30 AM - 09:00 AM).

- The traffic volume is the most significant factor in predicting pollutant concentrations in any location.

- Spatial maps showed that increase in traffic volume leads to increase in air pollutants concentrations.

- As grades increase, there is an increase in vehicle interactions and a decrease in speeds.

- Air pollution levels reach maximum values at or near the traffic signals and decrease gradually as the distance from signals increases, because of traffic signals' effect on the vehicular speed (at signals the speed equals zero but vehicles' engines are ON, and as known in this case a vehicle consumes considerable amount of fuel so it produces high amount of emissions).

\section{References}

[1] Z. Abu Al-Salem, and N. Al-Hazim, "Effect of Vehicular Speed, Traffic Volume, and Road Grades on Air Pollution in Amman City (Case Study)," pp. 3-4, Jordan, Amman, 2015.

[2] B. L. Duffy, and P. F. Nelson, "Non-methane Exhaust Composition in the Sydney Harbour Tunnel: A Focus on Benzene and 1,3-butadiene," Atmos. Environ., vol. 30, pp. 2759-2768, 1996.

[3] M. Obaidat, "Spatial mapping of traffic noise levels at urban areas," pp. 13-14, Jordan, Amman, 2008.

[4] S. N. Rogak, S. I. Green, and U. Pott, "Use of Tracer Gas for Direct Calibration of Emission-factor Measurements in a Traffic Tunnel," J. Air Waste Manage. Assoc., vol. 48, pp. 545-552, 1998.

[5] D. Schwela, "Air Pollution and Health in Urban Areas," Reviews on Environmental Health.,vol. 15, no. 12, pp. 13-24, 2000.

[6] USEPA, Permit Guidance Manual on Hazardous Waste Land Treatment Demonstration. Final draft EPA - 530 /SW 86-032. Office of solid waste and emergency responses USEPA, Washington D.C, 2007. 